\title{
The effect of serum levels of vitamin D in stone recurrencein patients with urinary tract stone
}

\author{
Feramarz Mohammadalibeigi, Majid Shirani*, Mahsa Motamedi \\ Department of Urology, Shahrekord University of Medical Sciences, Shahrekord, Iran
}

\section{ART I C L E IN F O}

Article Type:

Original

\section{Article History:}

Received: 23 May 2017

Accepted: 20 September 2017

Published online: 10 November 2017

\section{Keywords:}

Vitamin D3

Urolithiasis

Urinary stone

\begin{abstract}
A B S T R A C T
Introduction: The role of vitamin D in kidney stone disease and its effect on stone formation is still controversial.

Objectives: To find out the possible role of $25(\mathrm{OH}) \mathrm{D} 3$ as an intrinsic factor in urinary calcium stone formers (SFs; individuals with one episode during the last 5 years and individuals with more than one episode during the last 5 years), we investigated the effect of serum levels of vitamin D on recurrence of urinary stones in SFs and control subjects (non-SFs).

Patients and Methods: A total of 30 patients with first episode of urolithiasis (group A) and 30 patients with more than one episode of urolithiasis during the last 5 years (group B) aged 18 or older enrolled in this study and underwent metabolic evaluation including the measurement of serum level of 25(OH)D3, parathyroid hormone $(\mathrm{PTH})$, calcium and uric acid. Thirty age and sex-matched patients who had never urinary stone episode (non-SFs) were considered as control group. The patients in this study were selected among those admitted in Urology Department of Kashani hospital during the last year. Individuals excluded from the study were subjects with hyperparathyroidism or with the previous history of hyperparathyroidism. Results: Mean level of $25(\mathrm{OH})$ D3 was positively correlated with recurrent stone (mean $19.89 \pm 7.6$ in the control group versus $47.21 \pm 19.77$ in the group with the recurrent stone disease). The recurrent stone group (SFs) had the higher serum level of $25(\mathrm{OH}) \mathrm{D} 3$ than the control. No correlation was observed between the serum levels of PTH and 25(OH) D3 $(r=0$. $13, P=0.11$ ) in both control and urinary SFs group.

Conclusion: High serum level of vitamin D has an important effect on the pathogenesis of repeated urolithiasis. High serum levels of $25(\mathrm{OH}) \mathrm{D} 3$ were detected in the group with recurrent kidney stone disease. But it seems there was no relation between serum level of vitamin D3 and one episode of urolithiasis. Based on the results of this study, the high level of vitamin D3 may have a significant role in inducing the recurrence of urinary stone.
\end{abstract}

Implication for health policy/practice/research/medical education:

High levels of vitamin D3 may have a significant role in inducing the recurrence of urinary stones.

Please cite this paper as: Mohammadalibeigi F, Shirani M, Motamedi M. The effect of serum levels of vitamin D in stone recurrencein patients with urinary tract stone. J Renal Inj Prev. 2018;7(2):78-83. DOI: 10.15171/jrip.2018.19.

\section{Introduction}

Kidney stones are the third common urinary tract disease after prostate problems and urinary tract infections $(1,2)$. Around $80 \%$ to $85 \%$ of kidney stones are made up of calcium. Several factors can cause the formation of different types of urinary stones in patients. These factors are including environment, genetics, changes in the urinary concentration of crystallized molecules and the availability of natural-chemical macromolecules that make up the matrix of urinary stones, and also the urinary concentration of physiological inhibitors of crystallization $(3,4)$. Some studies suggested that the most likely causes for increasing prevalence of urinary tract stones are changes in people's lifestyle and dietary choices (4). After the formation of the first stone, the possibility of stone recurrence is very high. During 5 to 10 years after the first stone, its risk may be more than $50 \%(5,6)$.

The role of medical treatment is to prevent the growth of 
older stones or to prevent the formation of new stones. These treatments are long-term and should continue even throughout patients' life. On the other hand, it is recommended to make a change in the diet and lifestyle to prevent the recurrence of stones. This may be painful for patients and sometimes it may result in several side effects. However, this recommendation is not necessary for half of patients who are not at risk of recurrence stone. Hence it is necessary to identify patients at higher risk of recurrent stones for reducing of treatment costs and increasing of patient satisfaction. Vitamin D is a fat-soluble vitamin that acts as a pleiotropic hormone as well. Vitamin D undergoes sequential hydroxylations and reaches to a final active form of 1,25-dihydroxy vitamin $\mathrm{D}$ that interacts with its nuclear receptor (VDR) to modulate gene expression and to exert its biological effects (7). Vitamin D is crucial for proper functions of a wide variety of organ systems. Additionally, it is the main steroid hormone involved in the mineral ion homeostasis. The trend of VDR to connect to $1,25(\mathrm{OH}) 2 \mathrm{D} 3$ is approximately three times more than its tendency for binding to the other vitamin $\mathrm{D}$ metabolites. In case of vitamin $\mathrm{D}$ intoxication, a sharp rise in the amount of 25(OH)2D may be occurred due to its direct interaction with VDR. Separation of 1,25(OH)2D3 from its protein binding can cause an increase in bioavailability of the active hormone and lead to hypercalcemia (8). Any genetic defects in VDR may cause changes in metabolism of calcium and increasing the risk of stone formation. Allelic variation in VDR gene can reflect at least agenetic component involved in the formation of urinary tract stones (9).

\section{Objectives}

Vitamin D3 plays an important role in the metabolism of calcium oxalate in the body. It seems that vitamin D3 has an important role in development and recurrence of stones in the urinary tract. Additionally, its measurement is easy and relatively inexpensive. To our knowledge, this is the first study to compare the serum levels of vitamin D in patients with recurrent urinary tract stone compared to first stone formers (SFs) and non-SFs.

\section{Patients and Methods}

\section{Study population}

This cross-sectional descriptive study was performed in Kashani hospital, Shahrekord University of Medical Science, Shahrekord (January 2014 to January 2015). Patient referred to the Urology Department for urinary stone intervention was selected for this study. Around 90 patients were randomly selected. Study populations were limited to patients (age $\geq 18$ years) with a history of one or more past-history of kidney stone. Patients were selected based on the radiographic and sonographic evidence of urolithiasis. Healthy subjects who had no urinary stone in the radiological and clinical examinations served as control. The three groups of 30 individuals aged 18 or older enrolled to this study and underwent metabolic evaluation including the measurement of serum levels of $25(\mathrm{OH}) \mathrm{D} 3$, parathyroid hormone $(\mathrm{PTH})$, calcium and uric acid. All cases were matched by age, gender, occupation and then assigned to one of the three groups; A (patients with the first episode of urolithiasis), B (patients with more than one episode of urolithiasis during the last 5 years) and $\mathrm{C}$ (subject without urinary stone). In this study demographic questionnaires were used to collect information such as age, gender, family history of kidney stones, history of urinary tract stones, history of diabetes, hypertension and other complications, administration of thiazide diuretics and the use of sun care products. The body mass index (BMI) was calculated too.

Serum levels of uric acid, vitamin D3, calcium and PTH measured and chemical stone analysis performed. The following patients were excluded from this study; patients with anatomical abnormalities in urinary tract such as medullary sponge kidney, horseshoe kidneys and urinary tract obstruction, sarcoidosis, hyperparathyroidism, noncalcium urolithiasis and non-cooperative patients.

\section{Serum calcium, PTH and vitamin D measurement}

Total calcium was assessed using the Roche Diagnostics colorimetric assay on a Hitachi 912 analyzer (Roche Diagnostics, UK). Intact serum PTH (iPTH) levels were assessed by an electrochemiluminescence immunoassay (ECLIA) on the Elecsys Module (Roche Diagnostics, UK). Vitamin D level of serum was measured with enzymelinked immunosorbent assay (ELISA) method using OCTEIA 25-hydroxyvitamin D direct ELISA kits. This method determines vitamin $\mathrm{D}$ level $(\mathrm{ng} / \mathrm{mL})$ based on polarized light diversion in the range of 1.25 to $150 \mathrm{~nm}$. A falsely low or falsely high value of vitamin D may be obtained through vitamin D supplementation. Hence, patients were asked whether they taken supplementation. This was an exclusion from the study.

\section{Ethical issues}

The research followed the tenets of the Declaration of Helsinki; informed consent was obtained from all patients. This study was approved by Ethics Committee of Shahrekord University of Medical Sciences. All participants were informed about the objectives of the study and assured that the information will remain confidential. Participants also signed out consent forms.

\section{Data analysis}

The analysis was conducted in three groups including A (patients with the first episode of urolithiasis), B (patients with more than one episode of urolithiasis during the last 5 years) and C (subject without urinary stone). Statistical values are shown as means \pm standard deviation (SD). Mean levels of vitamin D, calcium, uric acid and iPTH in all three groups were compared using the unpaired $t$ test. Categorical variables were compared using the chi- 
square test and $P<0.05$ was considered significant. Data were analyzed using SPSS version 20 software (SPSS Inc., Chicago, IL).

\section{Results}

In this study, the mean age of the participants (ranging from 18 to 64 years old) was $45 \pm 12.3$ years. The average serum levels of iPTH, Ca, vitamin D3 and uric acid were $36.93 \pm 25.98 \mathrm{pg} / \mathrm{mL}, 9.57 \pm 0.68 \mathrm{mg} / \mathrm{dL}, 29.02 \pm 11.68 \mathrm{ng} /$ $\mathrm{mL}$ and $5.3 \pm 0.98 \mathrm{mg} / \mathrm{dL}$, respectively. Chi-square analysis showed no relationship between gender and the formation of urinary tract stones $\left(\chi^{2}=0.074, P=0.964\right)$. Table 1 demonstrates results of group $\mathrm{C}$ and $\mathrm{A}$. The mean serum levels of vitamin $\mathrm{D}$ in groups $\mathrm{C}$ and $\mathrm{A}$ were respectively, $19.8 \pm 7.6 \mathrm{ng} / \mathrm{mL}$ and $19.9 \pm 7.6 \mathrm{ng} / \mathrm{mL},(P>0.05$; Table 1$)$. Table 2 demonstrates the results of group $\mathrm{A}$ and $\mathrm{B}$. Accordingly, to assess laboratory parameters of the group with more than one episode of urolithiasis during the last five years (B) and the group with the first episode of urolithiasis (A) showed, mean of serum levels of vitamin $\mathrm{D}$ in groups $\mathrm{B}$ and A were respectively, 47.21 $\pm 19.77 \mathrm{ng} /$ $\mathrm{mL}$ and $19.98 \pm 7.61 \mathrm{ng} / \mathrm{mL}(P<0.05$; Table 2$)$.

Table 3 demonstrates the results of group $B$ and C. Likewise, to investigate of laboratory parameters of the control group (C) and the group with more than one episode of urolithiasis during the last five years (B), we found mean of serum level of vitamin D in group B (47.21 $\pm 19.77 \mathrm{ng} /$ $\mathrm{ml})$ was significantly $(P<0.05)$ higher than that of group C (19.98 $\pm 7.61 \mathrm{ng} / \mathrm{mL})$ (Table 3$)$.

Table 4 demonstrates results in group $\mathrm{A}+\mathrm{B}$ and $\mathrm{C}$. Similarly to analyze laboratory parameters of the control group $(\mathrm{C})$ and the group with the episode of urolithiasis $(A+B)$ using $t$ test indicated that mean serum levels of vitamin $\mathrm{D}$ in subjects with episode of urolithiasis $(\mathrm{A}+\mathrm{B})$ was significantly higher than that of control group (C), respectively $34.07 \pm 20.36 \mathrm{ng} / \mathrm{mL}$ versus $19.89 \pm 7.67 \mathrm{ng} /$ $\mathrm{mL}(P<0.05$, Table 4$)$.

With the elimination of BMI as a confounding variable in this study, we found a significant positive correlation between vitamin $\mathrm{D}$ and uric acid $(P<0.05, r=0.25)$. Between serum vitamin $\mathrm{D}$ and $\mathrm{Ca}$ was also a significant correlation $(P<0.05, r=0.20)$. However, no significant correlation between vitamin $\mathrm{D}$ and $\mathrm{iPTH}$ was detected while its correction tended to be negative $(P>0.05$, $r=-0.13)$.

Since the increase in BMI may be involved in the formation and recurrence of urinary tract stones, we decided to analyze the data in two separated categories; BMI below $24.9 \mathrm{~kg} / \mathrm{m}^{2}$ and BMI more than $25 \mathrm{~kg} / \mathrm{m}^{2}$. Among the participants in this study, $16.5 \%$ had BMI less than 24.9 $\mathrm{kg} / \mathrm{m}^{2}(40.7 \%$ without urinary tract stone and $59.3 \%$ with urinary tract stone) and $83.5 \%$ had BMI more than 25 $\mathrm{kg} / \mathrm{m}^{2}$ (2.5\% without urinary tract stone and $94.8 \%$ with urinary tract stone). As presented in Table 5 for BMI $>25$

Table 1. The results of laboratory parameters of control group $(C)$ and the group with first episode of urolithiasis $(A)$

\begin{tabular}{lcccc}
\hline Group & $\mathbf{2 5}(\mathbf{O H}) \mathbf{D 3}(\mathrm{ng} / \mathrm{mL})$ & Uric acid $(\mathrm{mg} / \mathrm{dL})$ & $\mathrm{Ca}(\mathrm{mg} / \mathrm{dL})$ & $\mathrm{iPTH}(\mathrm{pg} / \mathrm{mL})$ \\
\hline C & $19.8 \pm 7.6$ & $5.02 \pm 0.8$ & $9.6 \pm 0.5$ & $40.15 \pm 27.66$ \\
A & $19.9 \pm 7.6$ & $5.09 \pm 1.3$ & $9.4 \pm 0.8$ \\
$P$ value & $>0.05$ & $>0.05$ & $>0.05$ & $33.96 \pm 16.88$ \\
\hline
\end{tabular}

Table 2. The results of laboratory parameters of the group with more than one episode of urolithiasis during the last 5 years (B) and the group with first episode of urolithiasis (A)

\begin{tabular}{lcccc}
\hline Group & $\mathbf{2 5}(\mathbf{O H}) \mathbf{D} \mathbf{( n g} / \mathbf{m L})$ & Uric acid $(\mathbf{m g} / \mathbf{d L})$ & Ca $(\mathbf{m g} / \mathrm{dL})$ & $\mathrm{iPTH}(\mathbf{p g} / \mathrm{mL})$ \\
\hline A & $19.98 \pm 7.61$ & $5.08 \pm 1.3$ & $9.44 \pm 0.8$ & $33.9 \pm 21.8$ \\
$B$ & $47.21 \pm 19.77$ & $5.87 \pm 1.04$ & $9.83 \pm 0.6$ & $36.7 \pm 28.4$ \\
$P$ value & $<0.05$ & $<0.05$ & $<0.05$ & $<0.05$ \\
\hline
\end{tabular}

Table 3. The results of laboratory parameters of the group with more than one episode of urolithiasis during the last five years (B) and control group (C)

\begin{tabular}{lcccc}
\hline Group & $\mathbf{2 5}(\mathrm{OH}) \mathrm{D3}(\mathrm{ng} / \mathrm{mL})$ & Uric acid $(\mathrm{mg} / \mathrm{dL})$ & $\mathrm{Ca}(\mathrm{mg} / \mathrm{dL})$ & $\mathrm{iPTH}(\mathrm{pg} / \mathrm{mL})$ \\
\hline C & $19.8 \pm 7.6$ & $5.02 \pm 0.8$ & $9.6 \pm 0.5$ & $40.15 \pm 27.66$ \\
B & $47.21 \pm 19.77$ & $5.87 \pm 1.04$ & $9.83 \pm 0.6$ & $36.7 \pm 28.4$ \\
$P$ value & $<0.05$ & $<0.05$ & $<0.05$ & $<0.05$ \\
\hline
\end{tabular}

Table 4. The results of laboratory parameters of the control group $(C)$ and the group with the episode of urolithiasis $(A+B)$

\begin{tabular}{lcccc}
\hline Group & $\mathbf{2 5}(\mathbf{O H}) \mathbf{D} 3(\mathbf{n g} / \mathrm{mL})$ & Uric acid $(\mathrm{mg} / \mathrm{dL})$ & $\mathrm{Ca}(\mathrm{mg} / \mathrm{dL})$ & $\mathrm{iPTH}(\mathbf{p g} / \mathrm{mL})$ \\
\hline $\mathrm{C}$ & $19.89 \pm 7.68$ & $5.02 \pm 0.85$ & $9.66 \pm 0.5$ & $40.15 \pm 27.66$ \\
$\mathrm{~A}+\mathrm{B}$ & $34.07 \pm 20.36$ & $5.49 \pm 1.25$ & $9.64 \pm 0.7$ & $35.38 \pm 25.29$ \\
$P$ value & $<0.05$ & $>0.05$ & $>0.05$ & $>0.05$ \\
\hline
\end{tabular}


$\mathrm{kg} / \mathrm{m}^{2}$, the serum level of vitamin $\mathrm{D}$ in the group with the episode of urolithiasis $(\mathrm{A}+\mathrm{B})$ was significantly higher than that of the control group $(C)(P<0.05)$.

The analysis of tested parameters in participants with BMI below $24.9 \mathrm{~kg} / \mathrm{m}^{2}$ showed that the serum level of vitamin $\mathrm{D}$ in the group with the episode of urolithiasis $(\mathrm{A}+\mathrm{B})$ was higher than that of the control group (C) (Table 6).

Comparing the results of two groups with urinary tract stone (A and B) in category below $24.9 \mathrm{~kg} / \mathrm{m}^{2}$, we found that serum levels of vitamin $\mathrm{D}$ in group with more than one episode of urolithiasis during the last 5 years $(48.42 \pm 19.8 \mathrm{ng} / \mathrm{mL})$ was higher than that of the group with the first episode of urolithiasis $(19.68 \pm 7.5 \mathrm{ng} / \mathrm{mL})$ $(P<0.05)$ (Table 7$)$.

\section{Discussion}

In the present study, evaluation of roles of $1,25(\mathrm{OH}) 2 \mathrm{D} 3$ in calcium SFs revealed a correlation between levels of $1,25(\mathrm{OH}) 2 \mathrm{D} 3$ and stone recurrence. We found, levels of $1,25(\mathrm{OH}) 2 \mathrm{D} 3$ were significantly increased in recurrent calcium SFs compared to first SFs and control cases. The active form of vitamin $\mathrm{D}_{3}-1,25(\mathrm{OH}) 2 \mathrm{D} 3$ - is the most potent stimulator of intestinal calcium absorption. Calcitriol acts on bone and kidney in addition to its action in increasing intestinal calcium absorption leading to a further increase of serum calcium. As we know hypercalciuria is the most common abnormality identified in calcium SFs. High urinary calcium concentration leads to increased urinary saturation of calcium salts and stone formation (10).

The relationship between 25(OH) vitamin D3 levels and hypercalciuria has been reported in several studies. Berlin et al evaluated the effect of vitamin D3 on the levels of calcium in the urine of patients with urinary tract stone. They reported, the group of patients with high urinary calcium excretion also had significantly higher levels of 25-hydroxyvitamin D3 than the group of patients with low calcium excretion (11). Siener et al reported that patients with idiopathic hypercalciuria had higher serum concentrations of $1,25(\mathrm{OH}) 2 \mathrm{D} 3$ than normocalciuric SFs (12). Similarly, they also found that serum 1,25(OH)2D3 levels in renal SFs were higher than of control group (12). In all of the above studies, they did not separate first SFs from recurrent SFs. To our knowledge, this is the first study related to the role of vitamin D in recurrent SFs compared to first SFs. In the present study, a strong relationship between $1,25(\mathrm{OH}) 2 \mathrm{D} 3$ and recurrent stone formation was found that may be due to higher urinary calcium excretion in these patients. Despite no significant differences of serum vitamin D3 levels between the control group and the group with the first episode of urolithiasis, however vitamin $\mathrm{D}$ can play an important role in stone recurrence in patients with urinary tract stones.

Studies have shown that a subgroup of patients with idiopathic hypercalciuria fails to reduce urinary calcium excretion under dietary calcium restriction or fasting suggesting a primary disorder in renal tubular calcium reabsorption $(13,14)$. The underlying mechanism is still not clear, although the vitamin $\mathrm{D}$ dependent on expression of renal $\mathrm{CaR}$ might be the cause. Several studies have shown that high $1,25(\mathrm{OH}) 2 \mathrm{D} 3$ concentration associated with increased urinary calcium excretion may responsible for this condition $(15,16)$. This hypothesis can explain high $1,25(\mathrm{OH}) 2 \mathrm{D} 3$ concentration in our patients with

Table 5. The results of tested parameters in control group $(\mathrm{C})$ and groups with the episode of urolithiasis $(\mathrm{A}+\mathrm{B})$ in category with $\mathrm{BMI}>25$ $\mathrm{kg} / \mathrm{m}^{2}$

\begin{tabular}{lcccc}
\hline Group & $\mathbf{2 5}(\mathrm{OH}) \mathrm{D} \mathbf{3}(\mathrm{ng} / \mathrm{mL})$ & Uric acid $(\mathrm{mg} / \mathrm{dL})$ & $\mathrm{Ca}(\mathrm{mg} / \mathrm{dL})$ & $\mathrm{iPTH}(\mathrm{pg} / \mathrm{mL})$ \\
\hline C & $22.81 \pm 7.34$ & $4.8 \pm 0.8$ & $9.6 \pm 0.4$ & $40.47 \pm 28.25$ \\
A+B & $34.31 \pm 20.86$ & $5.5 \pm 1.2$ & $9.7 \pm 0.6$ & $36.36 \pm 25.52$ \\
$P$ value & $<0.05$ & $>0.05$ & $>0.05$ & $>0.05$ \\
\hline
\end{tabular}

Table 6. The results of tested parameters in the control group $(C)$ and the group with the episode of urolithiasis $(A+B)$ in category with BMI below $24.9 \mathrm{~kg} / \mathrm{m}^{2}$

\begin{tabular}{lcccc}
\hline Group & $\mathbf{2 5}(\mathrm{OH}) \mathrm{D} \mathbf{( n g} / \mathrm{mL})$ & Uric acid $(\mathrm{mg} / \mathrm{dL})$ & $\mathrm{Ca}(\mathrm{mg} / \mathrm{dL})$ & $\mathrm{iPTH}(\mathrm{pg} / \mathrm{mL})$ \\
\hline C & $15.64 \pm 6.2$ & $5.2 \pm 0.8$ & $9.7 \pm 0.6$ & $39.68 \pm 28.21$ \\
A+B & $29.6 \pm 6.25$ & $4.4 \pm 1.3$ & $8.3 \pm 1.5$ & $17.36 \pm 8.49$ \\
$P$ value & $<0.05$ & $>0.05$ & $<0.05$ & $>0.05$ \\
\hline
\end{tabular}

Table 7. The results of laboratory parameters of the group with more than one episode of urolithiasis during the last 5 years (B) and the group with the first episode of urolithiasis (A) in category with BMI below $24.9 \mathrm{~kg} / \mathrm{m}^{2}$

\begin{tabular}{lcccc}
\hline Group & $\mathbf{2 5}(\mathrm{OH}) \mathrm{D3}(\mathrm{ng} / \mathrm{mL})$ & Uric acid $(\mathrm{mg} / \mathrm{dL})$ & $\mathrm{Ca}(\mathrm{mg} / \mathrm{dL})$ & $\mathrm{iPTH}(\mathrm{pg} / \mathrm{mL})$ \\
\hline B & $48.4 \pm 19.8$ & $5.9 \pm 1.02$ & $9.8 \pm 0.6$ & $38.35 \pm 28.69$ \\
A & $19.6 \pm 7.5$ & $5.1 \pm 1.32$ & $9.5 \pm 0.7$ & $34.30 \pm 22.22$ \\
$P$ value & $<0.05$ & $<0.05$ & $>0.05$ & $>0.05$ \\
\hline
\end{tabular}


recurrent stone formation.

Several studies demonstrated the relationship between VDR polymorphisms and hypercalciuria in those with recurrent urinary tract stones $(17,18)$. In other study, only the relationship between serum levels of vitamin D3 and the level of calcium in the urine with renal stones have been confirmed. However, Kristina et al concluded that consuming vitamin D3 supplements did not increase the levels of calcium in the urine of vitamin D3 deficient postmenopausal women without urinary tract stones (19). In contrast, Leaf et al described that the consumption of vitamin D3 supplements in patients with vitamin D3 deficiency and urinary tract stone resulted in increasing of serum levels of vitamin D3, although the remarkable change was not seen in the level of calcium in the urine during 24 hours. This study showed that in patients with vitamin D3 deficiency and urinary tract stone, no concerns regarding the prescription of vitamin D3 supplements exists. However, it recommended monitoring the level of urine calcium during 24 hours periodically (20). Accordingly, Fallahzadeh et al found that serum levels of vitamin D3 were higher in the children with urinary tract stone compared with control group (21). In accordance with the above mentioned studies, our study showed, serum levels of vitamin D3 was significantly higher in the group with recurrent stone than those who had a urinary stone for the first time or the control group. However, the study of Tang et al presented serum levels of vitamin D3 in individuals with urinary tract stone and did not show significant a difference compared to control group, but they did not separate recurrent from first SFs (22). We found no significant difference in serum levels of vitamin D3 in the group with urinary stone for the first time in comparison with control group. To find the impact of vitamin D3 and PTH on calcium levels of urine in patients with recurrent urinary tract stone, Tae Kim et al detected a relationship between $1,25(\mathrm{OH}) \mathrm{D} 3$ levels and serum calcium. They found levels of vitamin D3 was higher in the group with hypercalciuria and stone recurrence (23). However, serum levels of vitamin D3 had no relationship with PTH value in patients with recurrent stones. In our study also, no association of $1,25(\mathrm{OH}) 2 \mathrm{D} 3$ with PTH in SFs was detected. Altered regulation of $1,25(\mathrm{OH}) 2 \mathrm{D} 3$ rather than $\mathrm{PTH}$ might be the primary intrinsic factor for the pathogenesis of calcium SFs.

In our study no significant difference in serum vitamin $\mathrm{D}$ between the control group and first SFs was detected but higher serum vitamin D in recurrent SFs suggests the limitation of vitamin D supplementation in these group of SFs.

\section{Conclusion}

This study was aimed to evaluate the impact of serum levels of vitamin D on recurrent SFs. In general, individuals with urinary tract stones had higher levels of vitamin D3 compared to the control group. No significant difference of serum vitamin D3 in control group (C) compared with the group with the first episode of urolithiasis (A) was seen. Serum levels of vitamin D3 were significantly higher in the group with more than one episode of urolithiasis during the last five years (B) compared with the control group (C). The results of our study suggested that the measurement of the level of vitamin $\mathrm{D}$ can be considered as one of the effective factors in recurrent urinary tract stone to separate the patients who are at higher risk.

\section{Limitations of the study}

Our study was conducted on a limited proportion of patients. We suggest investigating calcium levels of urine in the future similar studies.

\section{Authors' contribution}

MM conceived the study and MS performed the experiments. AM analyzed the data. AS drafted the final manuscript; all authors read, revised and approved the final manuscript.

\section{Conflicts of interest}

The authors declare no conflict of interest.

\section{Ethical considerations}

Ethical issues (including plagiarism, data fabrication, double publication) have been completely observed by the authors.

\section{Funding/Support}

The study was approved by ethics committee of Shahrekord University of Medical Sciences (ethical code\# 92-11-23).

\section{References}

1. Stoller ML. Chapter 16. Urinary stone disease. In: Tanagho EA, McAninch JW, eds. Smith's General Urology. 17th ed. New York: McGraw-Hill; 2008:203-227.

2. Yarger WE. Urinary tract obstruction. In: Brenner BM, Rector FC, eds. The Kidney. Philadelphia: Saunders; 1991:1768-1808.

3. Wein AL, Kavoussi LR, Novick AC, PartinAW, Peters CA. Textbook Urology Campbell Walsh(n). 9th ed. USA: Saunders; 2002:1363.

4. Taylor EN, Curhan GC. Body size and 24-hour urine composition. Am J Kidney Dis. 2006;48:905-915. doi: 10.1053/j.ajkd.2006.09.004.

5. Oussama $A$, Touhami $M$, Barkim $M$. In vitro and in vivo study of lemon juice on urinarylithogenesis. Arch Urol. 2005;58:1087-92.

6. Wassertein AG. Nephrolithisis, acutemanagement and prevention. Dis Mon 1998;44:196.

7. Takeda E, Yamamoto H, Taketani Y, Miyamoto K. Vitamin D-dependent rickets type I and type II. Acta Paediatr Jpn 1997;39:508-13.

8. Richard Bringhurts F, Marie Demay B, Stephan Krane M. Bone and minerals metabolism in health and disease. In: Dan L, Anthony S, Dennis L, eds. Harrisons Principles 
of Internal Medicine. 18th ed. New York: McGraw-Hill Medical; 2012:3092-4.

9. Simforoosh N, Mahmoodnejad N.Urinary Stone. In: Simforoosh N, Nouralizade A, eds. General Urology. 1st ed. Tehran: Teimourzadeh Tabib; 2010.

10. Bushinsky DA, Parker WR, Asplin JR. Calcium phosphate supersaturation regulates stone formation in genetic hypercalciuric stone-forming rats. Kidney Int. 2000;57:55060. doi:10.1046/j.1523-1755.2000.00875.x.

11. Berlin T, Holmberg I, Bjorkhem I. High circulating levels of 25-hydroxyvitamin D3 in renal stone formers with hyperabsorptive hypercalciuria. Scand J Clin Lab Invest. 1986;46:367-74.

12. Siener R, Glatz S, Nicolay C, Hesse A. Prospective study on the efficacy of a selective treatment and risk factors for relapse in recurrent calcium oxalate stone patients. Eur Urol. 2003;44:467-74.

13. Elkoushy MA, Sabbagh R, Unikowsky B, Andonian S. Prevalence andmetabolic abnormalities of vitamin D-inadequate patients presentingwith urolithiasis to a tertiary stone clinic. Urology. 2012;79:781-5. doi: 10.1016/j. urology.2011.09.004.

14. Yao J, Kathpalia P, Bushinsky DA, Favus MJ. Hyperresponsiveness of vitamin D receptor gene expression to 1,25-dihydroxyvitamin D3: a newcharacteristic of genetic hypercalciuric stone-forming rats. J Clin Invest. 1998;101:2223-32. doi: 10.1172/JCI1164.

15. Assadi F. Approach to the patient with nephrolithiasis; The Stone Queze. Iran J ped. 2007;17:283-292.

16. Quan V, Kalin A. Sensitivity to meat proteinintake and hyperoxaluria in idiopathic calciumstone formers.
Kidney Int. 2001:59;2273-81. doi: 10.1046/j.15231755.2001.00744.x.

17. Ozkaya O, Soylemezoglu O, Misirlioglu M. Polymorphisms in the vitamin D receptor gene and the risk of calcium nephrolithiasis in children. Eur Urol. 2003;44:150-4.

18. Ferreira LG, Pereira AC, Heilberg IP. Vitamin D receptor and calcium-sensing receptor gene polymorphisms in hypercalciuric stone-forming patients. Nephron Clin Pract. 2010;114:135-44. doi: 10.1159/000254386.

19. Kristina LP, Andrea PNJ, Stephen YN, Karen EPH. Vitamin $\mathrm{D}$ repletion does not alter urinary calcium excretion in healthy postmenopausal women. BJU Int. 2009;104:15126. doi: 10.1111/j.1464-410X.2009.08559.x.

20. Leaf DE, Korets R, Taylor EN, Tang J, Asplin JR, Goldfarb DS. Effect of vitamin D repletion on urinary calcium excretion among kidney stone formers. Clin J Am Soc Nephrol. 2012;7:829-34. doi: 10.2215/CJN.11331111.

21. Fallahzadeh MH, Zare J, Al-Hashemi GH, Derakhshan A, Basiratnia M, Arasteh MM, et al. Elevated serum levels of Vitamin D in infants with urolithiasis. Iran J Kidney Dis. 2012;6:186-91.

22. Tang J, McFann KK, Chonchol MB. Association between serum 25-hydroxyvitamin D and nephrolithiasis: The national health and nutrition examination survey III, 198894. Nephrol Dial Transplant. 2012;27:4385-9. doi: 10.1093/ ndt/gfs297.

23. Kim WT, Kim YJ, Yun SJ, Shin KS, Choi YD, Lee SC, et al. Role of 1,25-Dihydroxy vitamin D3 and parathyroid hormone in urinary calcium excretion in calcium stone formers.Yonsei Med J. 2014;55:1326-32. doi: 10.3349/ ymj.2014.55.5.1326.

Copyright ( $\odot 2018$ The Author(s); Published by Nickan Research Institute. This is an open-access article distributed under the terms of the Creative Commons Attribution License (http://creativecommons.org/licenses/by/4.0), which permits unrestricted use, distribution, and reproduction in any medium, provided the original work is properly cited. 